\title{
A projetada reforma do código civil*.
}

\author{
Sílvio Rodrigues \\ Catedrático de Direito Civil na Faculdade \\ de Direito da Universidade de São Paulo.
}

Escolhi para tema desta preleção assunto já por mim abordado alhures, mas que, pela sua extrema atualidade e alta relevância, pareceu-me merecedor de maiores debates.

Tenho realmente a impressão de que a projetada reforma do Código Civil, é problema que preocupa enormemente o civilista, que deve, assim valer-se de tôda oportunidade, para versá-lo.

É certo que a matéria é ampla demais para se enquadrar nos estreitos limites de uma palestra. Mas, de qualquer maneira, estou persuadido de que a mera circunstância de debatê-la sèriamente, já representa vantagem, por chamar a atenção dos estudiosos, dos interessados, e dos homens mais cultos, para a importância da questão.

Como é sabido, há pouco mais de dois anos, o Govêrno da República decidiu reformar muitos dos Códigos vigentes, inclusive o Código Civil. Com êsse escopo confiou, a dois eminentíssimos jurisconsultos brasileiros, a tarefa de elaborar os anteprojetos.

Com efeito, como de início se decidiu separar o direito das obrigações, dos demais ramos do direito civil, o Govêrno designou o professor Caro Mário da Silva Pereira, da Universidade de Minas Gerais para preparar um anteprojeto de Código de Obrigações, e o professor Orlando Gomes, da

* Aula inaugural proferida na abertura dos cursos jurídicos do ano de 1964. 
Faculdade de Direito da Bahia para, com exclusão daquela matéria, projetar o Código Civil.

Atuando com sua conhecida diligência, o insigne professor bahiano apresentou o seu anteprojeto no início do ano passado, trabalho que foi publicado em abril de 1963.

Como a parte de obrigações apenas acaba de ser divulgada, minha exposição se circunscreve ao exame daquele primeiro anteprojeto.

Dividi minha preleção em três partes. Na primeira, data venia, examino alguns defeitos da projetada reforma. $\mathrm{Na}$ segunda analiso algumas das excelentes modificações sugeridas pelo anteprojeto. E na terceira, finalmente e a título de conclusão, contesto a oportunidade de uma reforma, integral, da codificação civil.

1. O primeiro inconveniente da projetada reforma é o desdôbro do código civil em dois códigos autônomos. Tal orientação foi adotada pelo legislador suíço, não por razões de ordem técnica ou de caráter científico, mas por circunstâncias históricas de menor importância, de todos conhecidas. Por isso o legislador brasileiro de 1916 desprezou a orientação da legislação suíça. Ora, nada aconselha a que hoje se abandone o antigo caminho para buscar o novo, a não ser o desejo de imitar. Nenhum argumento ainda foi dado para justificar essa mudança de critério, entre nós ainda mais incompreensível, quando se sabe que não se almeja a proceder à unificação do direito privado.

Aliás, o mero fato dos anteprojetos partirem de juristas cuja orientação é nitidamente diversa, constitui elemento capaz de quebrar a unidade, imprescindível em qualquer sistema de direito privado.

2. Entretanto, o maior defeito da projetada reforma é a supressão da Parte Geral do Código Civil. 
A Parte Geral do Código Civil é um conjunto de regras, (muitas de caráter teórico, é verdade), mas que são aplicáveis a todos os campos da parte especial; assim, por exemplo, as noções de coisa fungivel, ou de pessoa incapaz ou de frutos pendentes ou de ato ilícito, definidas na parte geral do Código Civil, se aplicam a todos os campos disciplinados em sua Parte Especial, ou seja, ao Direito de Família, ao Direito das Coisas, ao Direito das Obrigações, e ao Direito das Sucessões.

Ademais, a inserção de uma Parte Geral no Código Civil, oferece um lugar adequado para disciplinar os institutos da prescrição e da caducidade.

O codificador brasileiro de 1916 foi colhêr no Código Alemão de 1896, a idéia de dividir em duas partes o corpo de leis civis, contendo o primeiro um conjunto de normas gerais, que seriam aplicáveis à parte segunda, esta dedicada especificamente à disciplina dos vários ramos do direito civil.

A experiência brasileira revelou-se extremamente proveitosa, como ficou demonstrado no quase meio século de vigência de nossa atual legislação.

Entretanto, dando ouvido a uma crítica injusta, projetase suprimir a Parte Geral do Código Civil.

T'al supressão foi pela primeira vez sugerida na exposição de motivos que precedeu o Anteprojeto de Código de Obrigações de 1941, da lavra dos eminentes ministros 0 . Nonato, F. Azevedo e Hahnnemam Guimarães. A crítica que se dirigia a Parte Geral do Código era a de ser excessivamente teórica. Diziam aquêles juristas:

"A existência da parte geral no Código Civil resulta de um processo excessivo de técnica que dificulta o ensino e a apreensão imediata do sentido das normas jurídicas".

Não conheço novos argumentos a respeito, e o insigne autor clo Anteprojeto, quando interpelado no Instituto 
dos Advogados de São Paulo não os forneceu tampouco, limitando-se a apontar que o desdôbro do Código em dois códigos autônomos, implicava na supressão de sua Parte Geral.

O fato de conter normas de caráter técnico é mau argumento para suprimir-se a Parte Geral. As regras que hoje se encontram na parte inicial do Código Civil foram repetidas no Anteprojeto, por que são indispensáveis em qualquer sistema. Portanto o fato de terem elas caráter teórico, não conduziu a que fôssem suprimidas.

Com efeito. Tôda a teoria das pessoas, contida nos arts. 2 a 42 do Código Civil, foi reproduzida no Anteprojeto em análise; tôda a teoria dos bens, objeto dos arts. 43 a 69 do Código Civil, se encontra no Título I do Livro do Direito das Coisas, do Anteprojeto. Os 26 artigos da legislação vigente, com algumas modificações, são substituídos pelos 36 artigos projetados (ns. 328 a 357 ).

$\mathrm{E}$ quanto à teoria dos fatos jurídicos, disciplinada nos arts. 74 e seguintes do Código atual, tal matéria decerto aparecerá no projeto do Código de Obrigações, que ainda desconheço.

De modo que apenas se espalhou pelos vários livros da parte especial do texto projetado, as regras que se encontram em bloco na parte geral do Código vigente.

A desvantagem de tal procedimento é manifesta, porque muitas noções, que se encontram no Livro do Direito das Coisas, ou no Livro das Pessoas, do Anteprojeto, são aplicáveis no campo do Direito de Família, no das Sucessões ou das Obrigações. Muito melhor é o sistema vigente, que a reforma quer abolir.

3. Ao lado dessas duas críticas de caráter geral, poderia enfileirar não poucas modificações sugeridas pelo anteprojeto do professor Orlando Gomes, e que me parecem menos felizes. 
Assim, ressalto entre outras:

a) a idéia de representação dentro da sucessão testamentária, que despreza a tradicional noção de que a deixa testamentária é negócio iminentemente "intuitu personae".

b) a criação da obrigação do cônjuge desquitado de prestar alimento a seu antigo consorte, se êste necessitar, independente da idéia de inocência ou culpa. Dêsse modo, o marido que debalde tentou assassinar a espôsa, ou a mulher condenada por adultério, podem reclamar de seu antigo cônjuge pensão alimentícia, desde que o necessitem. Tal inovação parece desprezar a distinção entre alimentos devidos por fôrça de parentesco - e marido e mulher não são parentes - e alimentos devidos por fôrça do matrimônio.

c) também me parece sem razão a criação do direito de superfície.

$\mathrm{O}$ Anteprojeto às vêzes é extremamente audaz e noutras excessivamente tímido. Dou como exemplo de tal audácia a regra do parágrafo único do art. 152. Após cuidar dos pressupostos do desquite litigioso, que são os mesmos da legislação vigente, dispõe o texto citado que se no curso do processo forem comprovados fatos outros que não os argüidos, o juiz decretará o desquite se tais fatos evidenciarem a impossibilidade da vida em comum.

Tal dispositivo dá extraordinário poder ao juiz, pois amplia de maneira desmedida as hipóteses do desquite litigioso, que assim se dará, mesmo com a oposição de um cônjuge, e sem que se apresente um pressuposto legal, cada vez que o julgador se convencer da insuportabilidade da vida em comum.

Não me manifesto sôbre a conveniência ou inconveniência de tal regra. Apenas anoto que ela constitui passo violento dentro de nosso direito de família, protetor reconhecido do casamento, que em vez de facilitar, em regra dificulta o desquite. 
Por outro lado, o projeto por vêzes se apresenta tímido, e isso se dá, por exemplo, quando conserva o testamento nuncupativo, velharia que não se compreende nos tempos atuais, e que constitui elemento de insegurança e instrumento de fraude.

Tímido é o projeto, ainda, quando mantém institutos obsoletos como o direito de acrescer entre os herdeiros, matéria que só se encontra na moderna legislação em virtude de um enrraigado, e neste campo injustificável, amor à tradição. Advém o direito de acrescer de um excessivo respeito à vontade presumida do testador, respeito descabido quando se tem em vista que o próprio testador negligenciou em manifestar claramente o seu desejo.

Poderia enumerar algumas outras soluções que não me parecem felizes. Mas é tanta a minha ansiedade em enumerar as qualidades do Anteprojeto, que salto por sôbre aquelas.

Efetivamente. Provindo de um jurista do porte do professor Orlando Gomes, o Anteprojeto não podia deixar de apresentar inegáveis virtudes. $\mathrm{E}$ aqui aproveito o ensejo para ressaltar uma qualidade do trabalho que me parece das mais importantes. Embora partindo da incontestável premissa de que o interêsse social deve prevalecer ao do indivíduo, o professor Orlando Gomes agiu sempre com enorme equilíbrio evitando sacrificar o interêsse individual cada vez que isso nâo se impuzesse de maneira inexorável.

Passo a analisar algumas das inovações felizes do texto projetado.

No Livro I - Das pessoas - o projeto disciplina os direitos à personalidade e o direito ao nome, matéria em que nossa legislação ou era omissa, ou havia disciplinado de maneira incompleta.

No campo do direito de família, entre as muitas modificações de caráter técnico, entre as quais a distinção entre os casos de impedimentos matrimoniais, e casos de incapacidade matrimonial, algumas inovações devem ser realçadas. 
Assim, por exemplo a constante do inciso II, do art. 200, que permite ao marido a contestação da paternidade, se à época da concepção os cônjuges estavam notòriamente separados. Esta regra é completada pela do art. 234 do Anteprojeto.

De acôrdo com o Código (art. 340), contestação da paternidade só era possível quando a separação dos cônjuges fôsse legal, de modo que, mesmo que o casal estivesse separado de fato e a mulher vivendo com concubino, o pai continuava ser o marido, por fôrça da presunção legal, "Pater is est quem justae nuptiae demonstrant". Tal solução, num país em que a gente mais humilde em geral não se desquita, mas apenas se separa para juntar-se alhures, é realmente iníqüa.

Outra inovação, esta não ao Código, mas à Lei n. ${ }^{\circ} 883 / 49$, que permitiu o reconhecimento do adulterino após a dissolução da sociedade conjugal, é a constante do $\S$ único do art. 233.

$\mathrm{O}$ adulterino, mesmo antes da dissolução do casamento de seu pai adúltero, pode pleitear alimentos, correndo o processo em segrêdo de justiça. Esta é a lei atual, que o projeto repete. Apenas o projeto determina que, morto o progenitor adúltero, o reconhecimento independe de ação investigatória, podendo, entretanto ser a filiação impugnada pelos interessados.

Dentro do campo do Direito das Coisas o projeto transplanta para o Código a disciplinação da promessa irretratável de venda e do condomínio em edifícios, que hoje constituem objeto de leis estravagantes. A regulamentação dêste último assunto, feita com grande profỉciência, preenche um claro em nosso direito, pois lei atual, de 1928, dada sua vetustez, é incompleta e imperfeita.

Inovações de alta relevância são as que admitem a passagem forçada, quando o acesso fôr insuficiente e inadequado (art. 372), ou que, atribuem à propriedade do solo mediante indenização, àquele que de boa-fé plantou ou 
construíu em terreno alhêio, desde que a construção ou plantação exceda consideràvelmente o valor do terreno (art. 442).

Ambos os dispositivos envolvem uma desapropriação levada a afeito em atendimento direto a um interêsse privado; mas ambas se inspiram na idéia de que indiretamente é um interêsse público que está sendo atendido.

No último caso o texto impede a incidência da regra que dispõe dever o acessório seguir o principal. A solução projetada é sábia, pois num campo de relações patrimoniais o que deve prevalecer é a noção de valor.

O projeto, tendo em vista o maior valor da acessão, atribui-lhe a condição de principal, permitindo ao dono da acessão, se de boa-fé, a aquisição do terreno. Acho que tal solução é a que atende ao maior interêsse social, tanto mais que o expropriado, na hipótese, corroborou para o evento, ao menos com sua negligência.

Importante, são, ainda, as inovações no campo do direito das sucessões. Merecem realce, desde logo, as que dizem respeito à sucessão da companheira, e a da inclusão do cônjuge sobrevivente entre os herdeiros legitimários.

A legislação de proteção à companheira vem se esboçando, tìmidamente, no Brasil, embora uma jurisprudência, atenta à evolução de nossos costumes, tenha admitido soluções pretorianas que procuraram atender às suas necessidades. País, que a despeito de sua marcada vocação religiosa, abriga número imenso de casais unidos fora do matrimônio civil, o Brasil não pode ignorar a existência do concubinato, nem negar direitos à concubina. Daí a importância dêsse capítulo, dentro do Anteprojeto de Código Civil.

A inclusão do cônjuge entre os herdeiros necessários é outra medida de grande alcance. Aliás, a solução do projeto não é audaz, talvez mesmo possa ser acusada de tímida, pois não são poucos os juristas modernos que apregoam a conveniência de se alterar a ordem de vocação hereditária, para se colocar o cônjuge sobrevivente em posição de vantagem sôbre os ascendentes. 
Outro texto digno de aplauso é o art. 769 que determina a validade das alienações feitas pelo herdeiro aparente. $\mathbf{O}$ dispositivo, data venia, traz uma erronia, pois reclama a boa-fé do herdeiro alienante, quando a boa-fé exigivel é a do terceiro adquirente. Todavia, corrigido êste engano, a regra tem grande alcance, pois vem solucionar controvérsia que de há muito se instalou na doutrina e na jurisprudência, e que diz respeito à extensão do art. 1600 do Código Civil. Este artigo valida as alienações feitas pelo herdeiro excluído da sucessão, e o que se quer saber é se tal regra se aplica a todos os casos de herdeiro aparente, ou se sòmente aos casos de indignidade. O preceito em tela, uma vez corrigido, pode pôr fim à controvérsia.

Muitos seriam os aspectos dêste fascinante tema, que mereceriam ser examinados. Entretanto a exigüidade do lempo não o permite.

III.

O problema maior que o assunto enseja é o de saber da oportunidade de reforma do Código Civil. Acho que as questôes devem ser propostas no campo da necessidade, e no da conveniência, formulando uma dupla pergunta: É necessário reformar o Código Civil? E se fôr negativa a primeira resposta, cabe a segunda pergunta: É conveniente reformar o Código Civil?

Para se inserir no Código Civil vigente as modificações que a hora presente está reclamando, não se fêz necessária a sua integral substituição por outra lei. Muitas alterações foram trazidas ao Código de 1916 por leis subseqüentes e se se quiser apontar apenas umas poucas, dentre as mais recentes, bastaria lembrar a criação da promessa irretratável de venda, a possibilidade de reconhecimento dos adulterinos, a reestruturação da adoção e o nôvo estatuto da mulher casada. 
Tôdas essas reformas, algumas substanciais, foram Jevadas a efeito dentro da estrutura do Código Civil, que continua substancialmente o mesmo.

Se nos lembrarmos que o Código Civil Francês de 1804, com seu século e meio de existência, foi atualizado sem sacrifício de sua estrutura básica, e se tivermos em vista que o nosso Ciódigo ainda não fêz cinqüenta anos, talvez não tenhamos tanta pressa em modificá-lo. Pelo menos nós, os juristas, que de um certo modo somos apegados à tradição.

Se não é necessário, será ao menos conveniente substituir por um nôvo, o Código Civil de 1916? Ainda aqui prefiro a resposta negativa.

Embora o Código de 1916 seja, por assim dizer, um Código do século XIX - que de um certo modo se estendeu até a guerra de 1914-18 - êle, com as modificações que vem sofrendo e com as que no momento reclama, é um monumento que deve ser preservado, por atender bastante bem às nossas necessidades atuais.

Duas razões me conduzem a esta asserção.

A primeira é a de que vivemos num momento de grande agitação e incerteza, em que, para se dar um exemplo, muitas reformas de base apregoadas por uns, são vistas como subversivas por outros, ao mesmo tempo que as posições dêstes, são tidas como reacionárias por aquêles. Onde nos encontraremos dentro de um, dois, cinco ou dez anos?. Será num momento tão infirme como o atual que se deve reformar todo o direito privado? Entendo que não.

A segunda preocupação que, a meu ver, desaconselha a reforma radical da lei civil diz respeito à excelência do Código de 1916. Êle constitui um monumento grandioso, um bloco sólido, que se apresenta como um edifício admirável, em que tôdas as linhas são harmoniosas.

O texto projetado conserva a maioria das regras que se encontram no Código vigente. Mas não consegue conservar, - e ao fazer esta assertiva peço desculpas a seu 
ilustre autor - não consegue conservar a beleza e a limpidez de sua forma. A pena inspirada de Rur Barbosa, atuando como cinzel na pedra consistente, alcançou seu momento maior ao redigir aquêle conjunto de regras, onde se tem a impressão de que nenhuma palavra falta, e de que vocábulo nenhum é supérfluo. Seria quase impossivel alcançar igual excelência em trabalho humano.

Dada a possibilidade de se trazer para dentro do Código Civil as inovações que os tempos modernos estão a exigir, parece inconveniente a sua substituição por um nôvo Código.

Agradeço aos senhores a atenção que me deram. 